\title{
Examining Moral Foundations Theory through Immigration Attitudes
}

\author{
By Leda Nath ${ }^{*}$, Nicholas Pedriana ${ }^{ \pm}$, Christopher Gifford ${ }^{*}$, \\ James W. McAuley \& Marta Fülöp ${ }^{\S}$
}

\begin{abstract}
Moral foundations theory (MFT) explains how political and cultural attitudes are shaped significantly by people's moral intuitions; gut-level judgments about proper human behavior and social relationships. We examine the theory through the topic of immigration attitudes. Social scientists of various stripes have built a comprehensive research program studying public attitudes towards immigrants and immigration policy. Immigration is currently among the most contentious political issues in the United States and Europe-evidenced in part by the election of Donald Trump, the UK's Brexit vote, and the recent rise of nationalist parties on the continent. Drawing on MFT and using one politically diverse sample and one liberal-leaning sample, we conducted two experiments respectively, to test whether effects of political orientation on US immigration attitudes may be moderated by alternative moral framing of pro-immigration appeals. Data support hypotheses, and is consistent with theoretical claims about moral diversity and political attitudes generally. Also, results shed new light on how shifts in immigration attitudes, that is whether one entrenches further into an original position or is persuaded into a new attitude, depend on one's place on the political spectrum.
\end{abstract}

Keywords: moral foundations theory, moral foundations, immigration, attitudes, moral intuition, experiment

\section{Introduction}

Recent political developments in the US, Great Britain, and across Europe remind of the persistence of race and ethnic conflict in an increasingly globalized world. Accordingly, public attitudes towards immigrants and immigration policy have a longstanding history in the social sciences. Researchers have explored individual and structural-level data in both single-country and cross-national contexts over various time periods (e.g., Dustmann and Preston 2007, Ceobanu and Escandell 2010, Esses et al. 2017), and have identified key variables influencing immigration attitudes including income or class position, education, gender, race/ ethnic identity, religion, economic conditions, degree of labor market competition, etc. (for example, see Álvarez Gálvez et al. 2020, Otjes 2021, McDermott et al. 2019, Macdonald 2021). Some strands of research are grounded in individual-level

\footnotetext{
*Professor, University of Wisconsin -Whitewater, USA.

${ }^{ \pm}$Senior Lecturer, University of Wisconsin - Madison, USA.

Researcher, University of Huddersfield, UK.

Professor, University of Huddersfield, UK.

${ }^{\S}$ Scientific Advisor, Institute of Cognitive Neuroscience and Psychology, Hungarian Academy of Sciences, Eötvös, Loránd University, Hungary.
} 
theories based on self-interest and rational choice (see, Gerber et al. 2017, Malesevic 2002); others are tied to theories on group dynamics and prejudice including Allport's (1954) classic "contact" hypothesis (see also Pérez 2010, Yueh-Ting and Ottati 2002); social identity theory (see, Tajfel 1982, Tajfel and Turner 1986, Mangum 2019, Margolis 2018); and group threat (see, Ramos et al. 2020, Esses et al. 2006; Espinosa et al. 2018 and also Blumer 1958 for a general overview).

We build on this body of scholarship by exploring another theory to explain immigration attitudes: Moral Foundations Theory (MFT) (Haidt 2013). Anchored in moral and political social psychology, MFT argues that political and cultural attitudes are shaped significantly by people's moral intuitions; gut-level judgments about proper human behavior and social relationships that may underlie and/or transcend an individual's socio-economic status, educational attainment, race/ ethnicity, and other demographic variables that correlate with political and cultural attitudes (Haidt 2013, Graham et al. 2011, Graham et al. 2009). Building on prior MFT research, we employ experiments to analyze (1) whether an individual's attitudes towards immigration can be influenced or modified when framed in alternative moral language and (2) why.

\section{Moral Foundations Theory and Political Attitudes}

MFT is built upon on several core principles/arguments about morality and political attitudes. First, it identifies five fundamental moral foundations - and their opposites - shared to greater or lesser extents by people and societies across cultural and spatial contexts: care/harm; fairness/cheating; in-group loyalty/ betrayal; authority/subversion; and purity/degradation. Second, MFT research in the United States (US) has consistently found that an individual's moral intuitions are strong predictors of one's political identity and voting preferences (Graham et al. 2009, Franks and Scherr 2015, Nath et al. 2018). And third, liberals/ progressives consistently score high on the care and fairness foundations (together referred to as the "individualizing" moral foundations) and relatively low on the loyalty, authority, and purity foundations (together referred to as the "binding" moral foundations), while conservatives tend to score relatively high on all five (Haidt and Graham 2007). This finding has led some MFT scholars to conclude that in the US, conservatives are on average more morally diverse than liberals/ progressives (Haidt 2013, Smith et al. 2014).

MFT has been used to explore political sentiments on a wide range of divisive issues including stem-cell research (Clifford and Jerit 2013); governmentsponsored torture (Smith et al. 2014); environmental policy (Kidwell et al. 2013); conservation behavior (Wolsko et al. 2016); the social safety net (Day et al. 2014); climate change (Dawson and Tyson 2012) and crime and punishment (Silver and Silver 2017). This article follows this line of scholarship by using MFT to explore attitudes towards immigration numbers.

That conservatives and liberals/progressives fundamentally disagree on this issue is well-known; the latter is generally pro-immigrant and support laws to 
expand easier access to legal status or citizenship and favor social policies that give immigrants - legal or otherwise - opportunities and access to social resources such as education and health care. Conversely, conservatives generally favor laws and policies that restrict entry, impose harsher penalties for the undocumented, and limit or deny access to social programs. As is the case with other high-octane political issues, MFT offers a straightforward hypothesis for such competing views on immigration: liberals/progressives and conservatives are motivated by different moral foundations that translate to different attitudes toward immigration. For example, to the extent that liberals/progressives are highly driven by the care foundation, their attitudes are likely influenced by a deep sense of compassion and empathy for weaker social groups seeking freedom and opportunity for a better life. In addition, liberals/progressives tend to equate the fairness moral foundation with equality and nondiscrimination, particularly towards disadvantaged racial or ethnic groups to which many immigrants belong (Haidt 2013). Conservatives by contrast are more influenced by, for example, in-group loyalty that in this context may be defined as citizens and/or workers whose jobs are perceived to be threatened by outsiders; the fact that most immigration disputes today involve people of different racial/ethnic backgrounds may further tap into the in-group loyalty foundation.

That said, we do not view MFT as a zero-sum theoretical competitor to established research on attitudes towards outside groups; rather, we see it as adjunct to current knowledge because MFT and current theories of self-interest or group dynamics often converge in ways that complement and inform one another. For instance, the "group threat" hypothesis argues that "prejudice emerges as groups develop a sense of social position relative to one another" (Quillian 1995, p. 588). As originally outlined by Blumer (1958), dominant groups are likely to feel a sense of collective threat when they perceive their material resources, social status, and/or cultural identity are threatened or challenged by outside groups (e.g., immigrants). This sense of threat may be heightened when the size (perceived or otherwise) of outsider groups is large and/or under broader conditions of economic uncertainty or insecurity. When viewed through the lens of MFT, the group threat hypothesis is clearly connected to the moral foundation of in-group loyalty. To the extent that conservatives are on average more strongly influenced by this moral prerogative, they may be more likely to sense collective threat-and thus a heightened sense of in-group loyalty-particularly under unfavorable economic or political conditions. Put another way, MFT offers an explanation for why some groups (e.g., conservatives and liberals/progressives) differ so significantly in their sense of collective threat generally, and with respect to immigration specifically: because it is a partial consequence of underlying moral sensibilities that places group loyalty on a higher (or lower) moral plane. We explore other potential theoretical convergences further in our concluding section. 


\section{MFT and Moral Framing: Are Political Attitudes Malleable?}

In addition to establishing robust links between people's moral intuitions and their political values/preferences, one subset of MFT research in the US has examined whether political attitudes can be modified when liberal (or conservative) stances on issues are explicitly framed in liberal (or conservative)-friendly moral foundations language (see Wolsco et al. 2016, or Feinberg and Willer 2013). The entrenching hypothesis argues that both groups are likely to show even greater commitment to their political attitudes when exposed to resonant moral language. For example, conservatives with anti-abortion attitudes may express even greater anti-abortion attitudes if the issue is framed in the moral foundations language of, say, purity or traditional gender hierarchies; conversely, liberals with pro-choice attitudes may be even more pro-choice if the issue is framed in the moral foundations language of care and fairness towards women.

The persuasion hypothesis argues that when liberal (or conservative) stances on an issue are framed in moral foundations language favored by the other side, it may "persuade" those otherwise opposed to that stance to modify their attitudes in ways that lean, at least somewhat, towards that stance. For example, liberals are significantly more likely than conservatives to favor social policies designed to expand the opportunities and life-chances of disadvantaged racial/ethnic minorities. The persuasion hypothesis suggests that if this issue were framed in the language of, say, loyalty - in the sense that those minorities are loyal Americans who fought and died for the nation in current and past conflicts - conservatives may be more likely to show greater support for such pro-minority policies. And vice versa for conservative stances framed in liberal-resonant moral language.

Day et al. (2014) tested both hypotheses by examining respective conservative and liberal stances on several contested political issues. They found support for the entrenching hypothesis for both groups when liberal (or conservative) stances were framed in morally-resonant language. For the persuasion hypothesis however, they found differences between conservatives and liberals; conservatives were more likely to be persuaded towards liberal stances when they were framed in conservative-resonant moral language: "findings for the in-group [loyalty], authority, and purity foundations support the persuasion hypothesis as conservative respondents adopted more liberal attitudes following exposure to these foundations" (Day et al. 2014, p. 1567). Liberals by contrast "were relatively unaffected" (p. 1563) when conservative stances were framed in the liberal-resonant moral language of care and fairness.

Several US studies focused specifically on attitudes towards pro-environmental behaviors are consistent with Day et al.'s (2014) findings. Kidwell et al. (2013) found that liberals were more committed to pro-recycling and sustainability practices when moral framing was congruent with the liberal-resonant moral foundations of care and fairness (the entrenching hypothesis). Conversely, they found that conservatives expressed greater commitment to such pro-environmental behavior when exposed to moral foundations language emphasizing "duty and an obligation to adhere to authority" (the persuasion hypothesis). Feinberg and Willer (2013) similarly found that conservatives were more likely to adopt pro- 
environmental attitudes when framed in the conservative-leaning moral language of purity. Finally, they concluded in part that "while liberals did not generally differ across conditions, conservatives shifted substantially in the pro-environmental direction after exposure to [the binding moral foundations] ... of obeying authority, defending the purity of nature, and demonstrating one's patriotism to the United States" (p. 7).

Recall the aim of our study is to (1) examine whether an individual's attitudes towards immigration can be influenced or modified when framed in alternative moral language and (2) explain why. Following this body of research outlined above, we explore the entrenching and the persuasion hypotheses with respect to attitudes on US immigration numbers. Based on prior literature and the different moral foundation profiles of liberal-leaning and conservative-leaning individuals, the entrenching hypothesis suggests:

H1. Left-leaning participants in the individualizing pro-immigration appeal condition will support immigration significantly more than those in the binding pro-immigration appeal condition.

The persuasion hypothesis suggests:

H2. Right-leaning participants in the binding pro-immigration appeal condition will support immigration significantly more than those in the individualizing proimmigration appeal condition.

Finally, we furthermore take special note of the Wolsko et al.'s (2016) study noted above because we modeled our methodology on their experimental design, both of which we discuss in the following section.

\section{Methods}

We examine political orientation, moral foundations, and attitudes on immigration via an experimental design adapted from Wolsko et al.'s (2016) prior study, which examined conservation behaviors. The experimental procedure was such that after each participant gave informed consent, they were assessed on a twelve-item political orientation measure, and which included an item specifically on immigration. Following this, they experienced one of three conditions in the form of reading a morally framed pro-immigration appeal. Finally, they answered additional questions to assess the treatment, demographic information, and a final measure on immigration attitudes. Below we outline the sampling method, measures, and experimental conditions in more detail for each experiment.

\section{Experiment 1}

\section{$\underline{\text { Sample }}$}

We drew a stratified random sample of undergraduate courses from each of the five university units (i.e., College of Letters \& Arts, College of Curriculum \& 
Instruction, College of Business \& Economics, College of Arts \& Communication, and the General Education Program) at a Carnegie Classified "Baccalaureate" state university in the US Midwest. After gaining permission from the course instructors, we arranged to visit classes to administer the survey in person. All surveys were first randomized before distributing to students. After ample time was given for all students to complete their survey, they were collected and combined later with all surveys for analyses. This process yielded a random sample size of $\mathrm{N}=160$ students. It's important to note that while many scholars draw on university students to complete research experiments, and where those methods are apt for testing theoretical processes, those samples may be limited to a particular class of students (e.g., students from an introductory psychology course). For the purpose of our study, we opted to expand our sample across campus and to reach, as just noted, across all colleges and several disciplines. This provided us with a more diverse sample of participants, including across the political spectrum from which to randomly assign to the experimental conditions. This more diverse sample also aimed to help reduce effects from other forms of sampling bias one might find from participants from a single course.

Measures Included in the Survey

Below are the measures and manipulations in this first experiment.

\section{Political Orientation}

Participants were first assessed on their political orientation using a modified measure established by Nail et al. (2009). Participants were asked to reveal to what extent they were in favor or against "each of the following policies, practices, and political groups" on a seven-point Likert scale (i.e., where $1=$ strongly against to $7=$ strongly in favor): Legalization of same sex marriage; Punishing illegal immigration; Democrats; Republicans; Donald Trump; Conservatives; Increase military spending; Increasing immigration numbers; Less strict gun control; Liberals; Socialized medicine; and Feminists. Relevant items were reverse coded so all items rated in the same direction such that higher numbers indicated a more conservative political orientation. Next, a single political orientation variable was created by adding up all measures and dividing by the number of items (i.e., 12), resulting in the new political orientation measure (Cronbach Alpha reliability=0.90). Furthermore, we converted the new measure into a dichotomous one using the mean score of $3.42\left(\mathrm{~S}_{\mathrm{x}}=1.09\right)$ cut-off between "left" (i.e., 0) and "right" (i.e., 1) leaning participants. The two variables correlated highly with one another $\left(\mathrm{R}_{\mathrm{xy}}=0.82, \mathrm{p}<0.001\right)$.

\section{US Immigration Numbers}

After experiencing the experimental treatment, participants were asked the question, "Currently US immigration policies allow a certain number of people from different groups to enter the US each year; Overall, do you think the US should: a) decrease the number of people allowed to immigrate here legally; b) 
maintain the current number of people allowed to immigrate here legally; c) increase the number of people allowed to immigrate here legally."

\section{Demographics}

After the US immigration numbers question, participants answered a series of questions to measure demographic characteristics. For age, they were asked "How old are you in years?" Race was assessed with the question, "Which category below best reflects your race?" and with answer choices of African American, Asian/Pacific Islander, European American/White, Hispanic/Latino, Native American, Mixed, and Other (with an option to type in an answer). Consistent with how the US socially constructs non-minority versus minority racial groups, this variable was recoded so that European American/White participants were placed in one category (coded 0 ), and all others were in another category (coded 1). Finally, sex was assessed by the question, "What is your sex?" and with answer choices of male, female, or intersex. No participants chose the third category, so this measure was recoded as $0=$ male and $1=$ female.

\section{Experimental Conditions}

Following the political orientation measure, each survey included one of three experimental conditions in the form of a short message on its own page in the survey. It included a morally framed pro-immigration appeal along with two morally consistent images (see Appendix):

(1) the individualizing condition; moral framing emphasizing care and fairness:

Short message: Many caring citizens of the United States are concerned about the well-being of immigrants. We are interested in what you think and feel about this issue. First, please read through the brief public service announcement on the next page before answering a few additional questions.

Longer appeal: America has always been a country of immigrants. Since our founding, the United States has welcomed people from around the world who seek freedom and equality. Show you care for humanity by welcoming our vulnerable immigrants. By doing so, you are helping to ensure they have fair and equal access to the freedoms and protections our nation provides. Demonstrate your love of humanity by reducing the suffering of immigrants and help make sure that no one is denied their opportunity to live and work here. SHOW YOUR COMPASSION

(2) the binding condition: moral framing emphasizing in-group loyalty, authority, and purity:

Short message: Many patriotic citizens of the United States are concerned about the well-being of immigrants. We are interested in what you think 
and feel about this issue. First, please read through the brief public service announcement on the next page before answering a few additional questions.

Longer appeal: America has always been a country of immigrants. Since our founding, the United States has welcomed people from around the world who seek freedom and opportunity. Show your love for America's history and traditions by welcoming loyal and hard-working immigrants. By doing so, you will be honoring and strengthening our nation's sacred values. Demonstrate your love of country by following the many examples of our leaders who protect and welcome America's immigrants and their families.

SHOW YOUR PATRIOTISM!

(3) a neutral control condition.

Many people are concerned about the well-being of immigrants. We are interested in what you think and feel about this issue. Please answer some questions on the following pages.

Novelty

After participants read the message noted in their assigned condition, they were also asked to indicate the extent to which "you think the appeal gives reason for supporting immigration that is new," on a seven-point Likert scale (i.e., $1=$ strongly disagree to $7=$ strongly agree, with $4=$ neutral).

\section{Experiment 1 Results}

One hundred sixty undergraduate students from a mid-sized Midwestern university in the United States participated in an experiment with 55 in the Individualizing, 52 in the Binding, and 53 in the Control condition. The pretreatment value on a single immigration numbers measure, the political orientation measure plus its dichotomous left-right version, the main dependent variable of US immigration numbers and finally basic descriptive statistics may be seen in Table 1. Based on the twelve political orientation items measured on a scale of 1 to 7 , with higher numbers indicating more conservative orientation, participants averaged a score of $3.42\left(S_{x}=1.09\right)$. Using this mean score, we created a dichotomous left-right measure where left-leaning participants were counted if their score was less than 3.42, and right-leaning participants were counted if their score was greater than or equal to 3.42 . This indicated $57 \%$ participants to be "left" and $43 \%$ participants to be "right." In addition, other measures indicated $48 \%$ of the sample was female, $14 \%$ non-white, and the average age of participant was 21.20 years $\left(S_{x}=4.32\right.$ years $)$. Statistics also revealed that participants already generally held neutral or supportive views on immigrant numbers as indicated by a mean score of $3.99\left(S_{x}=1.23\right)$ and where $4=$ "neutral" on this pre-condition individual measure. 
Table 1. Experiment 1 Descriptive Statistics $(N=160)$

\begin{tabular}{|l|c|c|}
\hline & Mean/Percent & $\mathrm{S}_{\mathrm{x}}$ \\
\hline $\begin{array}{l}\text { Pre-treatment measure: } \\
\text { Lower immigration numbers } \\
\text { (1=strongly against; } \\
7=\text { strongly in favor) }\end{array}$ & 3.99 & 1.23 \\
\hline $\begin{array}{l}\text { Political Orientation } \\
(1 \text { to } 7,7=\text { most conservative) }\end{array}$ & & \\
\hline $\begin{array}{l}\text { Dichotomous Left-Right Political Orientation } \\
\text { (1=right) }\end{array}$ & 3.42 & 0.50 \\
\hline $\begin{array}{l}\text { Post-treatment measures: } \\
\text { US Immigration numbers: }\end{array}$ & 0.43 & 0.40 \\
Decrease numbers & $10.2 \%$ & \\
Maintain numbers & $49.7 \%$ & \\
Increase numbers & $40.1 \%$ & 0.50 \\
\hline Sex of participant & 0.48 & \\
$\quad$ (1=female) & & \\
Female & 77.0 & 4.32 \\
\hline Male & 83.0 & 0.35 \\
\hline Age in years & 21.20 & \\
\hline Race of participant & 0.14 & \\
(1=nonwhite) & & \\
\hline
\end{tabular}

After participants read the appeal, they were assessed on various factors including the extent to which they thought the appeal gives reason for supporting immigration that is "new." Recall, MFT scholars have found that in the US, conservatives are on average more morally diverse than liberals/ progressives in that they consider all five moral foundations more often (Haidt 2013, Smith et al. 2014). If this is the case, participants sorted into the "right" category would not likely view the individualizing message as containing more new information compared to the binding message. Conversely, participants sorted into the "left" category would likely perceive information in the binding message as containing significantly more new information compared to the individualizing condition. Based on the post-treatment question, "Please indicate the extent to which you think the appeal gives reason for supporting immigration that is new" with answer choices of $1=$ strongly disagree to $7=$ strongly agree, this assumption was supported. T-tests supported those assumptions, revealing "right" participants did not perceive the binding message $(M=3.70, S x=1.17)$ significantly different from the individualizing message $(\mathrm{M}=3.35, \mathrm{Sx}=1.15)$ in terms of offering novel information $(p<n s)$. "Left" participants on the other hand agreed significantly more that the binding message $(\mathrm{M}=4.13, \mathrm{Sx}=1.41)$ contained more new information compared to the individualizing message $(\mathrm{M}=3.33, \mathrm{Sx}=1.61 ; \mathrm{p}<0.05)$.

We hypothesized the effects of political orientation on immigration attitudes would be moderated by the framing of the pro-immigration appeal/message. The predicted direction of this effect stemmed from the entrenching and the persuasion hypotheses. The entrenching hypothesis suggests participants reading a message consistent with their own stance on a social issue and that matches their moral foundation framework will strengthen their stance compared to if they read the 
message in an alternative moral framework. The persuasion hypothesis however suggests different outcomes based on the political orientation of the participant. "Right" participants reading a message counter with their own stance on a social issue and in language matching their moral foundation framework will shift towards the counter stance.

In our sample, the pre-treatment item measuring participant's level of agreement on whether to "punish illegal immigration" and whether to "increase immigration numbers" differed based on the participants political ideology. T-tests indicated "left" oriented participants significantly agreed less with "punishing illegal immigration" with a score $(\mathrm{M}=2.79, \mathrm{Sx}=1.43)$ suggesting "moderately" to "mildly against" compared with "right" oriented participants whose mean fell close to a score of $5=$ "mildly in favor". $(\mathrm{M}=4.92, \mathrm{Sx}=1.47 ; \mathrm{p}<0.001)$. Similarly, "left" oriented participants significantly agreed more to increase immigration numbers with as mean score falling between "neutral" and "mildly in favor" $(\mathrm{M}=4.52, \mathrm{Sx}=1.23)$ compared with "right" oriented participants whose score fell between "neutral" and "mildly against" $(\mathrm{M}=3.45, \mathrm{Sx}=0.94 ; \mathrm{p}<0.001)$.

Results supported our hypotheses. T-tests revealed "left" participants in the individualizing condition $(\mathrm{M}=2.76, \mathrm{SD}=0.44)$ agreed to increase immigration numbers significantly more than those in the binding condition $(\mathrm{M}=2.43$, $\mathrm{SD}=0.57), \mathrm{p}<0.01$. Likewise, right-leaning participants in the binding condition $(\mathrm{M}=2.29, \mathrm{SD}=0.64)$ agreed to increase immigration numbers significantly more than those in the individualizing condition $(\mathrm{M}=1.77, \mathrm{SD}=0.61), \mathrm{p}<0.01$. Also, right-leaning participants in the binding condition $(\mathrm{M}=2.29, \mathrm{SD}=0.64)$ scored significantly higher than those in the control condition $(\mathrm{M}=1.90, \mathrm{SD}=0.44)$, $\mathrm{p}<0.05$. These results are consistent with MFT predictions.

Further support for our hypotheses came in analyses to examine whether the messages acted to moderate the effects of political ideology on immigration attitudes. Two-way analysis of variance revealed political orientation alone, and the interaction of political orientation with the experimental condition were both significant. The main effect for political orientation yielded an $F$ ratio of $F(1,142)$ $=42.134, \mathrm{p}<0.001$, indicating a significant difference between left $(\mathrm{M}=2.57$, $\mathrm{SD}=0.54)$ and right $(\mathrm{M}=1.98, \mathrm{SD}=0.60)$. The interaction effect was also significant, $\mathrm{F}(2,142)=7.10, \mathrm{p}<0.001$, indicating the condition moderated the effect of political orientation on immigration attitude. The experimental condition alone was not statistically significant (see Graph 1 for a depiction of these results). 
Graph 1. Experiment 1 on Immigration Numbers

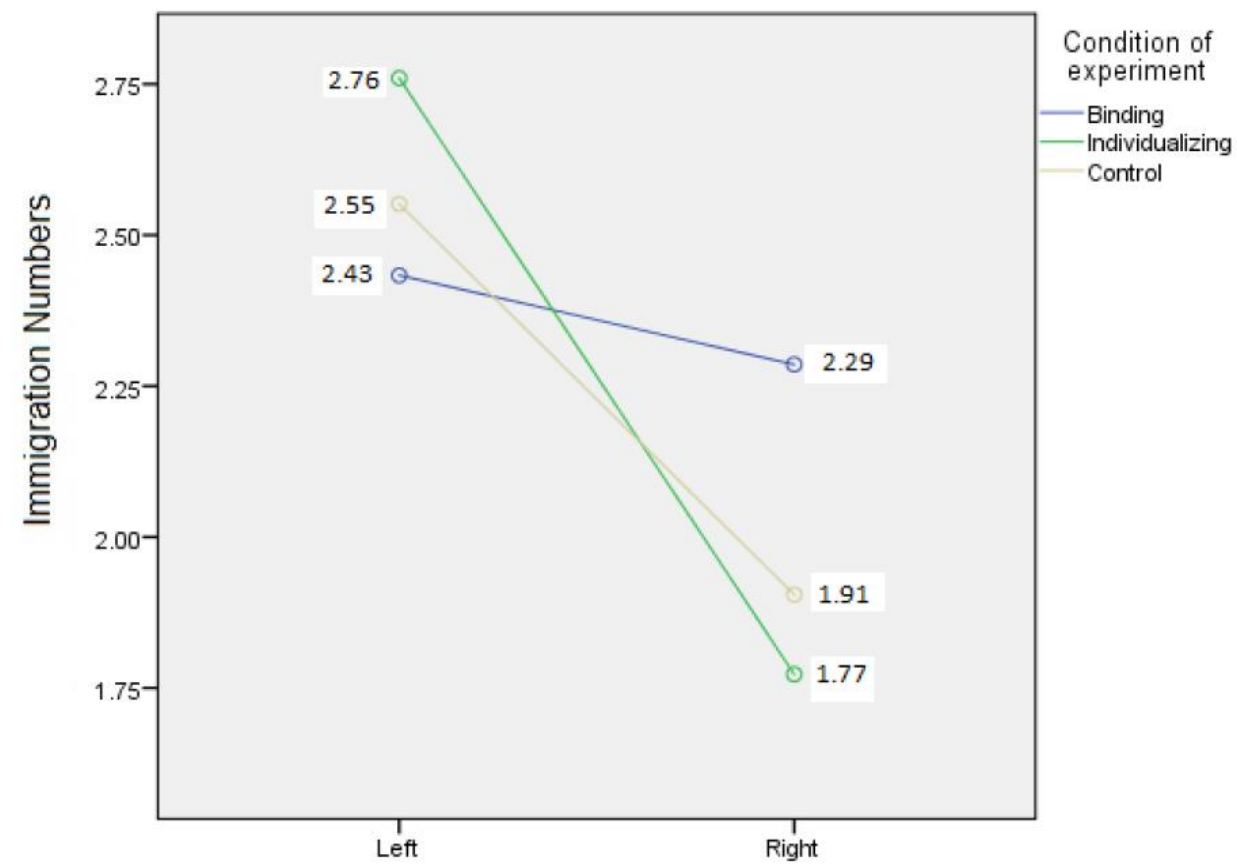

In effort to provide additional support, we conducted a second experiment in a different Midwestern university. Unlike in Experiment 1, which recruited a random sample of participants thereby providing a diverse student sample including in relation to political ideology, the sample in Experiment 2 was different. The majority of participants leaned left, which meant predictions according to MFT would shift as well. With a predominantly left-leaning sample, only the entrenching hypothesis would apply.

Also different from Experiment 1, Experiment 2 included an additional immigration-related variable. Besides measuring immigration numbers, a measure assessing support for policy related to amnesty was added (more details on this measure in the next section). Therefore, we had two hypotheses also in Experiment 2:

H3. Left-leaning participants in the individualizing pro-immigration appeal condition will support immigration significantly more than those in the binding pro-immigration appeal condition.

H4. Left-leaning participants in the individualizing pro-immigration appeal condition will support amnesty significantly more than those in the binding pro-immigration appeal condition.

In the following section, we outline Experiment 2 details.

\section{Experiment 2}

We executed a replication experiment at another Midwestern university, but this time a Carnegie Classified "Research I" (i.e., doctoral-granting university with 
"very high" research activity) location and with a sample that leaned predominantly left, confirmed with T-tests on relevant variables (i.e., Experiment 1's sample was significantly more conservative [M=3.42, $\mathrm{SD}=1.09]$ and agreed significantly less with the pre-treatment statement to increase immigration numbers $[\mathrm{M}=4.01$, $\mathrm{SD}=1.23]$ compared with Experiment 2's sample [M=2.77, $\mathrm{SD}=0.98, \mathrm{p}<0.001]$ and $[\mathrm{M}=4.57, \mathrm{SD}=1.20, \mathrm{p}<0.001]$, respectively). We also included an additional immigration-related variable linked with amnesty policy.

Sample

In Experiment 2, a single large introductory course gave permission to administer the survey used in Experiment 1. All surveys were first randomized before distributing in person to students. After ample time was given for all to complete their survey, they were collected and coded for analyses. This process yielded a sample size of $\mathrm{N}=282$ students.

\section{Measures Included in the Survey}

The measures included in Experiment 2 were mostly identical to those used in Experiment 1 . Some minor changes were made to some variables, and a new immigration-related measure on amnesty, as noted below.

\section{Political Orientation}

One difference was in political orientation which factored into two constructs (Cronbach Alpha reliability $=0.84$ and 0.85 , respectively) this time instead of one. It made theoretical sense however to consider all items together again and create a measure similar to that used in Experiment 1. Reliability analysis confirmed our decision (Cronbach Alpha reliability $=0.91$ ), and so we used all twelve items to form the single political orientation measure. Also similar to Experiment 1, we examined its histogram and created a dichotomous version splitting the variable at 3.00 on the 7 -point scale. The 12 -item political orientation measure and this dichotomous version correlated highly with one another $\left(R_{x y}=0.83, p<0.001\right)$.

\section{US Immigration Numbers}

This variable was slightly modified for Experiment 2. Two more answer categories were added for increased variance leading to the following five (new categories in italic): greatly decrease the number of people allowed to immigrate here legally; decrease the number of people allowed to immigrate here legally; maintain the current number of people allowed to immigrate here legally; increase the number of people allowed to immigrate here legally; and greatly increase the number of people allowed to immigrate here legally.

Amnesty

We added an additional measure related to immigration policy (in addition to the US Immigration Numbers measure). Adopted from Ayers et al. (2009), this new measure asked, "You may or may not know that in 1986 the US Congress 
passed the Immigration Reform and Control Act, which granted amnesty to nearly two million persons who had lived continuously in this country for four or more years without proper documentation. This amnesty law allowed these immigrants to remain here as permanent residents and to apply for US citizenship. At this time, do you think repeating this amnesty program would be:" with answer categories "a very bad thing," "a bad thing," "a good thing," and "a very good thing" coded 1-4, respectively.

\section{Demographics}

Also similar to Experiment 1, we examined the same demographic indicators (e.g., sex and race made dichotomous, and age).

\section{Experimental Conditions}

The experimental treatments were identical to those in Experiment 1. That is, following the political orientation measure, each survey included one of three experimental conditions in the form of a short message on its own page in the survey; a morally framed pro-immigration appeal along with two morally consistent images reflecting either the individualizing or binding moral framework, or a control message.

Novelty

Similar to Experiment 1, after participants read the appeal, they were asked to indicate the extent to which they thought "the appeal gives reason for supporting immigration that is new to $m e$ " on a scale of $1=$ strongly disagree to $7=$ strongly agree. The words, "to me" were added in Experiment 2's version.

\section{Experiment 2 Results}

Two hundred eighty-two undergraduate students from a large-sized Midwestern university in the United States participated in an experiment with 91 in the Individualizing, 95 in the Binding, and 97 in the Control condition. The pretreatment value on a single immigration numbers measure, the political orientation measure plus its dichotomous left-right version, the main dependent variable of US immigration numbers, amnesty, and finally basic descriptive statistics may be seen in Table 2.

Based on the twelve political orientation items measured on a scale of 1 to 7 , with higher numbers indicating more conservative orientation, participants averaged a score of $2.77\left(S_{x}=0.98\right)$, indicating a more liberal sample on average compared to participants in Experiment 1 (recall mean=3.42, $\mathrm{S}_{\mathrm{x}}=1.09$ ). The dichotomous left-right measure indicated $64.3 \%$ participants to be "left" and $35.7 \%$ participants to be "right," though "right" might arguably be better described as middle-left. In addition, other measures indicated $66 \%$ of the sample was female, 24\% non-white, and the average age of participant was 18.99 years $\left(S_{x}=1.02\right.$ years). Statistics also revealed that participants already generally held neutral or supportive views on immigrant numbers as indicated by a mean score of $3.43\left(S_{\mathrm{x}}=1.20\right)$ and where $4=$ "neutral" on the pre-condition measure. 
Table 2. Experiment 2 Descriptive Statistics $(N=282)$

\begin{tabular}{|c|c|c|}
\hline & Mean/Percent & $S_{x}$ \\
\hline $\begin{array}{l}\text { Pre-treatment measures: } \\
\text { Lower immigration numbers } \\
\text { (1=strongly against; } \\
7=\text { strongly in favor })\end{array}$ & 3.43 & 1.20 \\
\hline $\begin{array}{l}\text { Political Orientation } \\
\text { ( } 1 \text { to } 7,7=\text { most conservative })\end{array}$ & 2.77 & 0.98 \\
\hline $\begin{array}{l}\text { Dichotomous Left-Right Political Orientation } \\
\text { (1=right) }\end{array}$ & 0.36 & 0.48 \\
\hline $\begin{array}{l}\text { Post-treatment measures: } \\
\text { US Immigration numbers: } \\
\text { Greatly decrease numbers } \\
\text { Decrease numbers } \\
\text { Maintain numbers } \\
\text { Increase numbers } \\
\text { Greatly increase numbers }\end{array}$ & $\begin{array}{r}3.74 \\
0.4 \% \\
2.1 \% \\
33.0 \% \\
52.5 \% \\
12.1 \%\end{array}$ & 0.71 \\
\hline $\begin{array}{l}\text { Amnesty: } \\
\text { Very good thing } \\
\text { Good thing } \\
\text { Bad thing } \\
\text { Very bad thing } \\
\end{array}$ & $\begin{array}{r}3.11 \\
30.3 \% \\
54.1 \% \\
13.2 \% \\
2.5 \% \\
\end{array}$ & 0.72 \\
\hline $\begin{array}{l}\text { Sex of participant } \\
(1=\text { female })\end{array}$ & 0.66 & 0.48 \\
\hline Age in years & 18.99 & 1.02 \\
\hline $\begin{array}{l}\text { Race of participant } \\
\text { (1=nonwhite) }\end{array}$ & 0.24 & 0.43 \\
\hline
\end{tabular}

Results Examining Immigration Numbers

In Experiment 2 and due to the left-leaning sample, only the entrenching hypothesis applies. That is, in regard to the immigration numbers variable, we hypothesize participants in the individualizing condition would agree significantly more with increasing numbers than those in the binding condition (i.e., H3). In regard to the amnesty variable, we expect the same pattern; participants in the individualizing condition would view amnesty as significantly more a "good thing" compared to those in the binding condition (i.e., H4).

The study yielded support for the immigration numbers hypothesis. The main effect for experimental condition yielded an $\mathrm{F}$ ratio of $\mathrm{F}(2,266)=3.138, \mathrm{p}<0.05$, indicating the effect for condition was significant between the grand mean score for participants in the individualizing $(\mathrm{M}=3.78)$, binding $(\mathrm{M}=3.53)$ and control $(\mathrm{M}=3.63)$ conditions, and in the predicted direction. Similarly, political orientation also yielded an $\mathrm{F}$ ratio of $\mathrm{F}(1,266)=55.003, \mathrm{p}<0.001$, indicating a significant difference between participants in the left $(\mathrm{M}=3.95)$ versus the right $(\mathrm{M}=3.35)$ categories. The interaction of these two however, yielded an $\mathrm{F}$ ratio of $\mathrm{F}(2,266)=$ $0.110, n s$, suggesting one's political ideology did not matter when considering the condition effects. We would expect this however, given participants were predominantly left-leaning in both conditions. 
Furthermore, t-tests were performed within the politically "left" and "right" groups to further understand effects. Results revealed that among the "left" participants, those in the individualizing condition $(\mathrm{M}=4.09, \mathrm{SD}=0.63)$ indicated significantly more often to increase immigration numbers compared to those in the binding condition $(\mathrm{M}=3.81, \mathrm{SD}=0.79), \mathrm{p}<0.05$. That is, reading the message morally framed consistent with their own political orientation significantly increased liberal participants on immigration numbers. This offered more support for our immigration numbers hypothesis for the further left group. It was not supported however for participants in the "right" group, where those in the binding condition ( $\mathrm{M}=3.26, \mathrm{SD}=0.63)$ were not significantly different than those in the individualizing condition $(\mathrm{M}=3.47, \mathrm{SD}=0.61), n s$, though numbers were in the predicted direction (see Graph 2).

Graph 2. Experiment 2 on Immigration Numbers

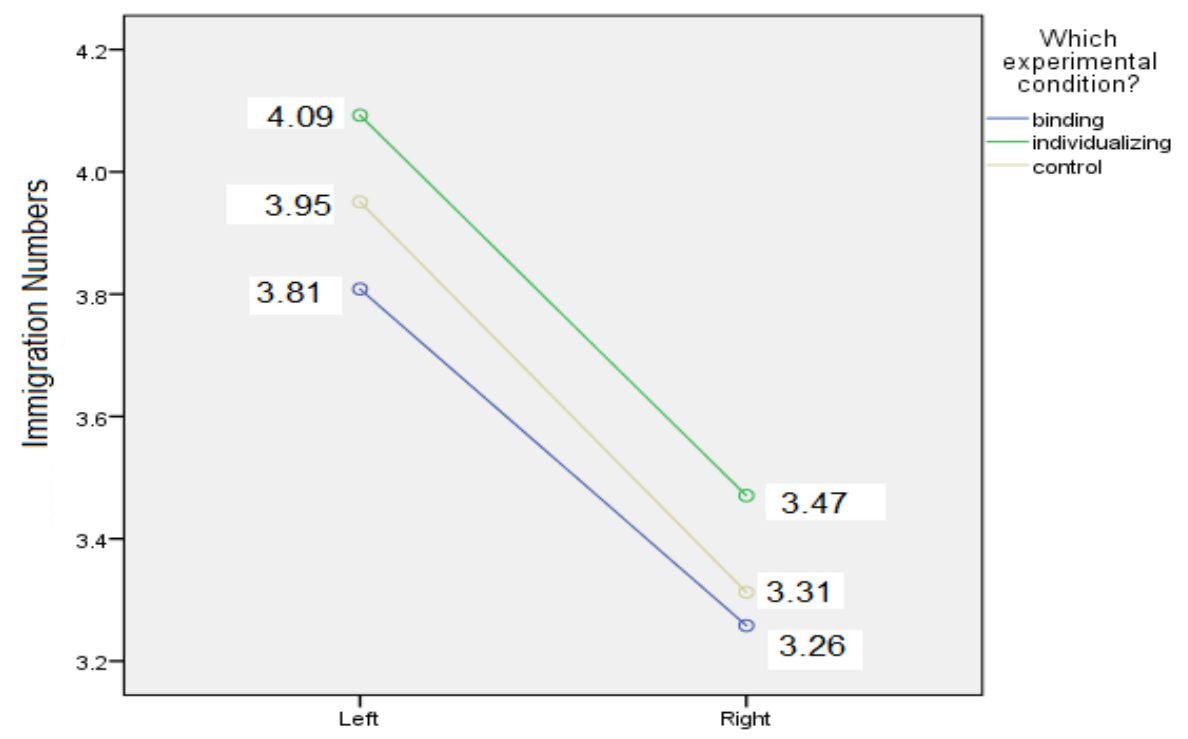

Results Examining Amnesty

In relation to the amnesty hypothesis, we found support. Recall, we hypothesized the effects of political orientation on amnesty would be moderated by the framing of the pro-immigration press release. Specifically, more liberal participants in the individualizing condition will favor amnesty significantly more than those in the binding condition.

The main effect for experimental condition yielded an $\mathrm{F}$ ratio of $\mathrm{F}(2,265)=$ $1.654, \mathrm{p}<0.01$, indicating the effect for condition was significant between the grand mean score for participants in the individualizing $(\mathrm{M}=3.10)$, binding $(\mathrm{M}=2.83)$ and control $(\mathrm{M}=3.04)$ conditions. Similarly, political orientation also yielded an F ratio of $\mathrm{F}(1,265)=139.818, \mathrm{p}<0.001$, indicating a significant difference between participants in the left $(M=3.42)$ versus the right $(M=2.56)$ categories. The interaction of these two however, yielded an $\mathrm{F}$ ratio of $\mathrm{F}(2,266)=0.044, n s$, suggesting one's political ideology did not matter when considering the condition effects. 
Furthermore, t-tests were performed within the politically "left" and "right" groups to further understand effects. Results revealed that among the "left" participants, those in the individualizing condition $(\mathrm{M}=3.53, \mathrm{SD}=0.50)$ indicated significantly more often to support amnesty compared to those in the binding condition $(\mathrm{M}=3.27, \mathrm{SD}=0.56), \mathrm{p}<0.01$. That is, reading the message morally framed consistent with their own political orientation significantly increased liberal participants on supporting amnesty. This was not true for participants in the "right" group however, where those in the binding condition $(\mathrm{M}=2.39, \mathrm{SD}=0.67)$ were not significantly different than those in the individualizing condition $(\mathrm{M}=2.67$, $\mathrm{SD}=0.69$ ), $n s$. Likewise, there were no other significant differences between all other combinations (see Graph 3).

Graph 3. Experiment 2 on Amnesty

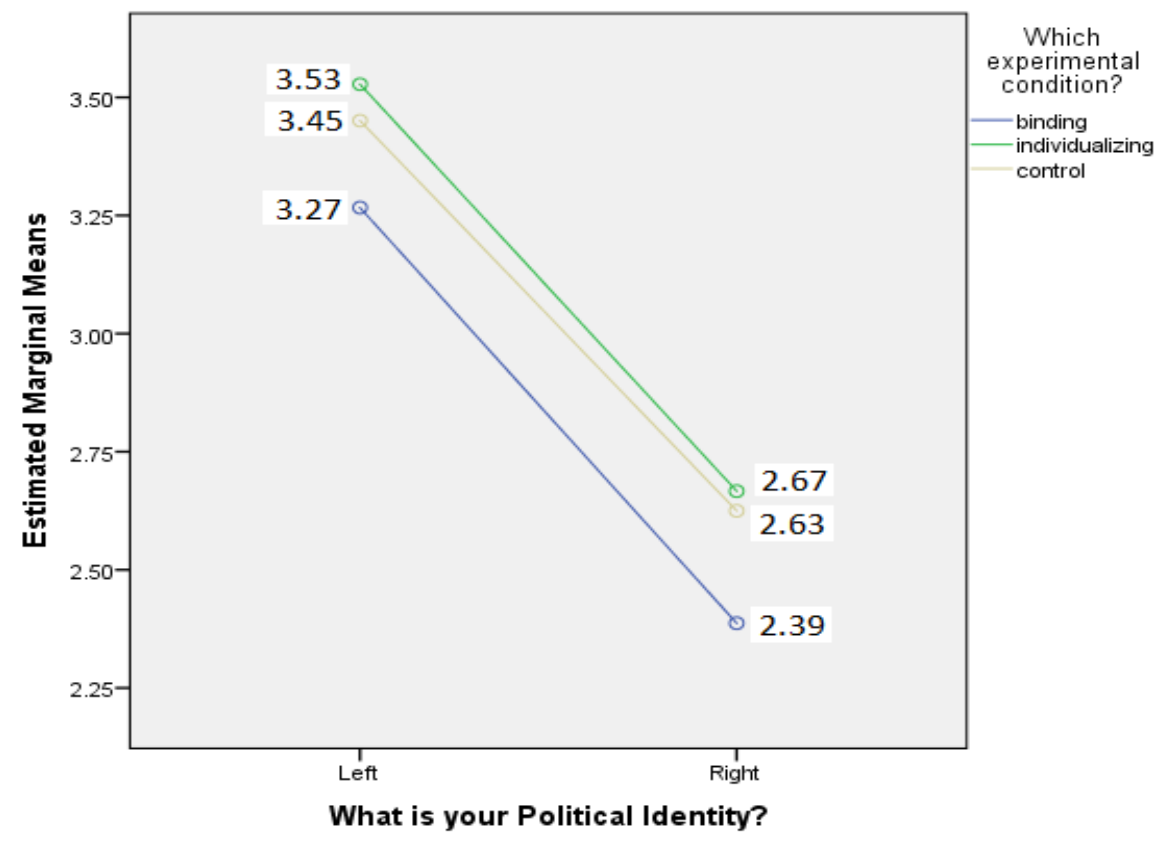

These results support hypotheses. Similar to results related to immigration numbers, for those participates more left, these results support the entrenching hypothesis which states reading a morally framed message consistent with your political orientation values will significantly increase your support for amnesty.

Finally, we examined whether participants viewed their message as containing reasons for supporting immigration that appeared "new" to them. Results indicated that among participants in the "left" group, they rated the binding message $(\mathrm{M}=2.78, \mathrm{SD}=1.35)$ as containing significantly more information that was "new" to them compared to the individualizing message $(\mathrm{M}=2.24, \mathrm{SD}=1.43), \mathrm{p}<0.05$. Participants in the "right" group however did not (Binding $\mathrm{M}=1.40, \mathrm{SD}=0.26$; Individualizing $\mathrm{M}=1.41, \mathrm{SD}=0.24, n s)$. This is surprising since in this study, our "right" group contains many left-leaning participants. Rather, it is consistent with moral foundation theory's assumptions that conservatives consider all five moral foundations more readily than do liberals, who rely primarily on two (i.e., fairness 
and caring). This aspect of difference between conservatives and liberals may be useful in explaining results.

\section{Discussion}

Two similar experiments with two unique samples from two different Midwestern universities were performed to examine if MFT helps explain attitudes on US immigration numbers. For both experiments and using the MFT framework, pro-immigration appeals were written in either the individualizing, binding, or a neutral moral language. We examined the entrenching and the persuasion hypotheses with respect to attitudes on US immigration numbers in both experiments, and also in relation to amnesty policy in the second experiment.

Predictions were driven by the MFT framework plus the sample characteristics. Given Experiment 1 included a more politically diverse sample and Experiment 2, a more left-leaning sample (see each sample's histogram in Figure 1 below), this meant predictions would vary depending on the entrenching and persuasion hypotheses. For Experiment 1, we predicted (i.e., H1-entrenching) liberal-leaning participants in the individualizing pro-immigration appeal condition will support immigration significantly more than those in the binding pro-immigration appeal condition. We also predicted (i.e., H2-persuation) conservative-leaning participants in the binding pro-immigration appeal condition will support immigration significantly more than those in the individualizing pro-immigration appeal condition. Results of experiment 1 were consistent with our predictions.

Figure 1. Histogram of Experiment 1 and Experiment 2 Samples on Political Ideology Measure

Experiment 1 Histogram

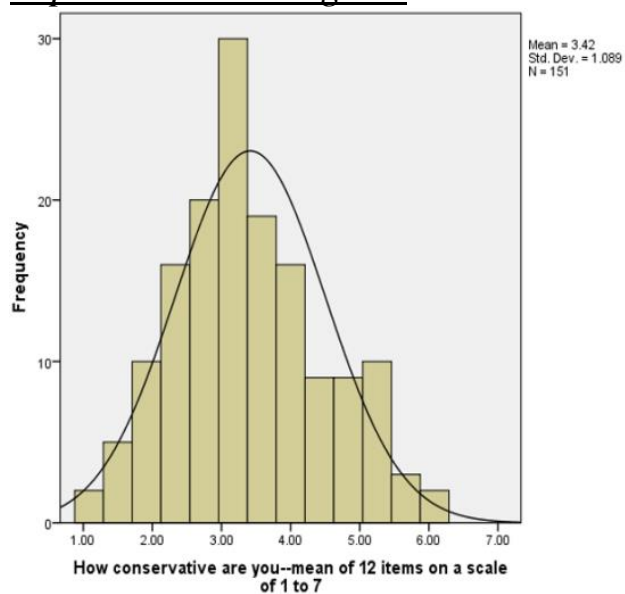

Experiment 2 Histogram

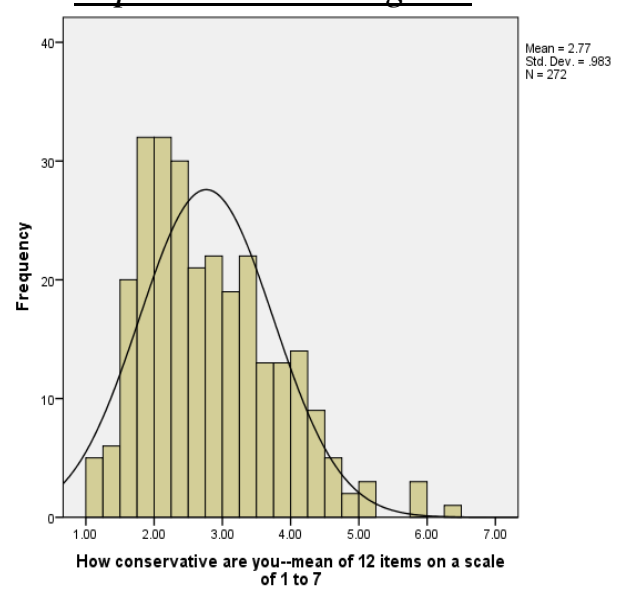

Predictions for Experiment 2 differed based on its more left-leaning sample. Predictions were consistent with the entrenching hypothesis, since most participants were left-leaning and already rather supportive of immigration. We predicted leftleaning participants in the individualizing pro-immigration appeal condition will support immigration significantly more than those in the binding pro-immigration 
appeal condition (i.e., H3). We also predicted left-leaning participants in the individualizing pro-immigration appeal condition will support amnesty significantly more than those in the binding pro-immigration appeal condition (i.e., H4). Results of Experiment 2 were consistent with these hypotheses.

\section{Conclusion}

Overall, results of both experiments reveal support for MFT in explaining immigration attitudes around immigration numbers and amnesty policy. Participants in the "left" increased support for immigration when reading the "individualizing" message, reflecting the entrenching hypothesis. Participants in the "right" increased support for immigration when reading the "binding" message, reflecting the persuasion hypothesis.

Our research also confirmed MFT assumptions that "right" leaning participants refer to a more diverse moral framework than "left" leaning participants. This was indicated in analysis of a post-treatment measure asking participants to rate the level of agreement to whether the message read contained information that was "new." "Right" leaning participants did not rate the "binding" message as significantly different from the "individualizing" message. "Left" participants however did rate the "binding" message as having more new information compared to the "individualizing" message.

This work provides further support for how direction and strength of attitude change may be contingent on the moral framing of the language used in messages. Writing to individuals in this study in the language they morally connect with has more influence than if using neutral or unfamiliar language. The individualizing condition includes language associated more often with those leaning liberal (Graham et al. 2009, Franks and Scherr 2015, Nath et al. 2018). For example, focus on fairness and caring connects with those more highly valued moral intuitions among liberals. The binding condition uses language more often associated with those leaning conservative. While fairness and caring may be included in a conservative-leaning moral framework, moral intuitions linked with loyalty, authority and purity are more often unique to those leaning conservative. Therefore, that messages may link with one politically oriented group versus another has a unique impact compared to any message written without reference to particular moral intuitions. That is, this research demonstrates how the entrenching and persuasion hypotheses depend on the political orientation of the participant as well, thus supporting the intersection of political ideology with moral framing in understanding attitude formations.

\section{References}

Allport GW (1954) The nature of prejudice. Reading: MA: Addison-Wesley.

Álvarez Gálvez J, Salinas Pérez JA, Martínez Cousinou G, Muniategi Azkona E, Antolínez Domínguez I (2020) Attitudes towards immigration at the regional level in Europe in times of crisis. Revista de Fomento Social 75(298): 297-325. 
Ayers JW, Hofstetter CR, Schnakenberg K, Kolody B (2009) Is immigration a racial issue? Anglo attitudes on immigration policies in a boarder county. Social Science Quarterly 90(3): 593-610.

Blumer H (1958) Race prejudice as a sense of group position. Pacific Sociological Review 1(1): 3-7.

Ceobanu AM, Escandell X (2010) Comparative analyses of public attitudes toward immigrants and immigration using multinational survey data: a review of theories and research. Annual Review of Sociology 36(1): 309-328.

Clifford S, Jerit J (2013) How words do the work of politics: Moral foundations theory and the debate over stem cell research. The Journal of Politics 75(3): 659-671.

Dawson SL, Tyson GA (2012) Will morality or political ideology determine attitudes to climate change. The Australian Community Psychologist 24(2): 8-25.

Day MV, Fiske ST, Downing EL, Trail TE (2014) Shifting liberal and conservative attitudes using moral foundations theory. Personality and Social Psychology Bulletin 40(12): 1559-1573.

Dustmann C, Preston I (2007) Racial and economic factors in attitudes to immigration, The BE Journal of Economic Analysis \& Policy 7(1): 11-30.

Espinosa A, Guerra R, Sanatkar S, Paolini S, Damigella D, Licciardello O, et al. (2018) Identity inclusiveness and centrality: investigating identity correlates of attitudes toward immigrants and immigration policies. Journal of Social Issues 74(4): 674-699.

Esses VM, Wagner U, Wolf C, Preiser M, Wilbur CJ (2006) Perceptions of national identity and attitudes toward immigrants and immigration in Canada and Germany. International Journal of Intercultural Relations 30(6): 653-669.

Esses VM, Hamilton LK, Gaucher D (2017) The global refugee crisis: empirical evidence and policy implications for improving public attitudes and facilitating refugee resettlement. Social Issues and Policy Review 11(1): 78-123.

Feinberg M, Willer R (2013) The moral roots of environmental attitudes. Psychological Science 24(1): 56-62.

Franks AS, Scherr KC (2015) Using moral foundations to predict voting behavior: regression models from the 2012 US presidential election. Analyses of Social Issues and Public Policy (ASAP) 15(1): 213-232.

Gerber AS, Huber GA, Biggers DR, Hendry DJ (2017) Self-interest, beliefs, and policy opinions: Understanding how economic beliefs affect immigration policy preferences. Political Research Quarterly 70(1): 155-171.

Graham J, Haidt J, Nosek BA (2009) Liberals and conservatives rely on different sets of moral foundations. Journal of Personality and Social Psychology 96(5): 1029-1046.

Graham J, Nosek BA, Haidt J, Iyer R, Koleva S, Ditto PH (2011) Mapping the moral domain. Journal of Personality and Social Psychology 101(2): 366-385.

Haidt J (2013) The righteous mind: why good people are divided by politics and religion. Allan Lane Publishers.

Haidt J, Graham J (2007) When morality opposes justice: conservatives have moral intuitions that liberals may not recognize. Social Justice Research 20(1): 98-116.

Kidwell B, Farmer A, Hardesty DM (2013) Getting liberals and conservatives to go green: Political ideology and congruent appeals. Journal of Consumer Research, 40(2): 350-367.

Macdonald D (2021) Immigration attitudes and white Americans' responsiveness to rising income inequality. American Politics Research 49(2): 132-142.

Malesevic S (2002) Rational choice theory and the sociology of ethnic relations. Ethnic and Racial Studies 25(2): 193-212. 
Mangum M (2019) Revisiting economic threat and cultural concerns: public opinion toward immigration and non-citizens by race. Social Science Research 83(Sep): 102309.

Margolis MF (2018) How far does social group influence reach? Identities, elites, and immigration attitudes. Journal of Politics 80(3): 772-785.

McDermott M, Knowles ED, Richeson JA (2019) Class perceptions and attitudes toward immigration and race among working-class whites. Analyses of Social Issues \& Public Policy 19(1): 349-380.

Nail PR, McGregor I, Drinkwater AE, Steele GM, Thompson AW (2009) Threat causes liberals to think like conservatives, Journal of Experimental Social Psychology 45(4): 901-907.

Nath L, Pedriana N, Gifford C, McAuley J (2018) Moral foundations theory and the 2016 US presidential election, Sociological Imagination 54(1): 75-85.

Otjes S (2021) Between "eradicate all false religion" and "love the stranger as yourself": how immigration attitudes divide voters of religious parties. Politics \& Religion 14(1): 106-131.

Pérez E (2010) Explicit evidence on the import of implicit attitudes: the IAT and immigration policy judgments. Political Behavior 32(4): 517-545.

Quillian L (1995) Prejudice as a response to perceived group threat: Population composition and anti-immigrant and racial prejudice in Europe. American Sociological Review 60(4): 586-611.

Ramos A, Pereira CR, Vala J (2020) The impact of biological and cultural racisms on attitudes towards immigrants and immigration public policies. Journal of Ethnic \& Migration Studies 46(3): 574-592.

Silver JR, Silver E (2017) Why are conservatives more punitive than liberals? A moral foundations approach. Law and Human Behavior 41(3): 258-272.

Smith IH, Aquino K, Koleva S, Graham J (2014) The moral ties that bind...even to outgroups: the interative effect of moral identity and the binding moral foundations. Psychological Science 25(8): 1554-1562.

Tajfel H (1982) Social psychology of intergroup relations. Annual Review of Psychology 33(Feb): 1-39.

Tajfel H, Turner J (1986) The social identity theory of intergroup behaviour. In S Worchel, WG Austin (eds.), Psychology of Intergroup Relations. Chicago: Nelson Hall.

Wolsko C, Ariceaga H, Seiden J (2016) Red, white, and blue enough to be green: effects of moral framing on climate change attitudes and conservation behaviors. Journal of Experimental Social Psychology 65(Jul): 7-19.

Yueh-Ting L, Ottati V (2002) Attitudes toward US immigration policy: the roles of ingroup-out-group bias, economic concern, and obedience to law. Journal of Social Psychology 142(5): 617-634. 


\section{Appendix}

Individualizing Condition Images
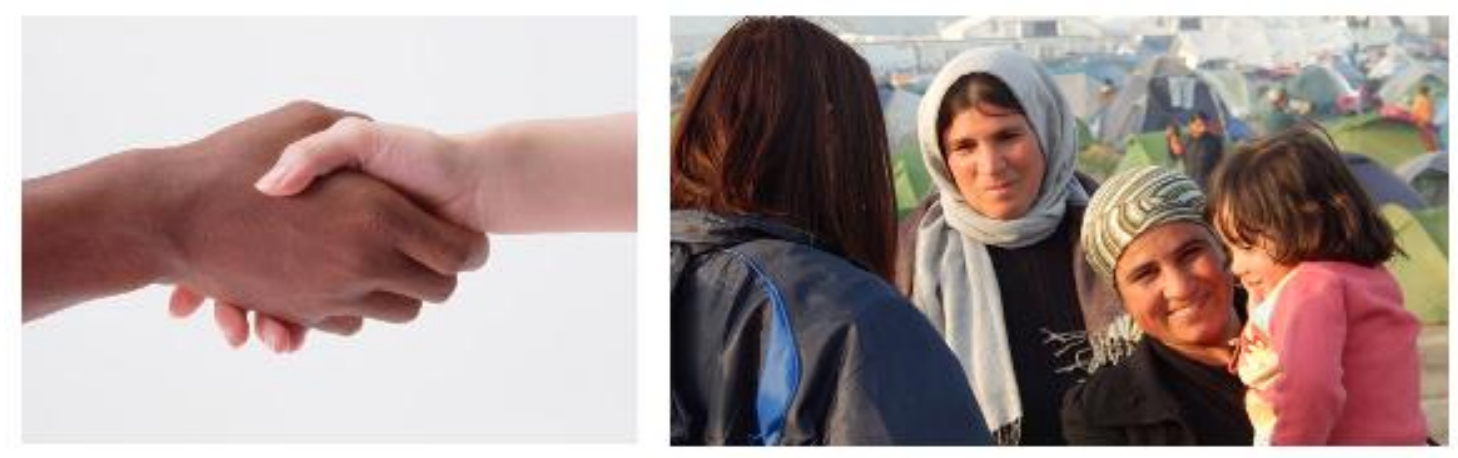

Binding Condition Images
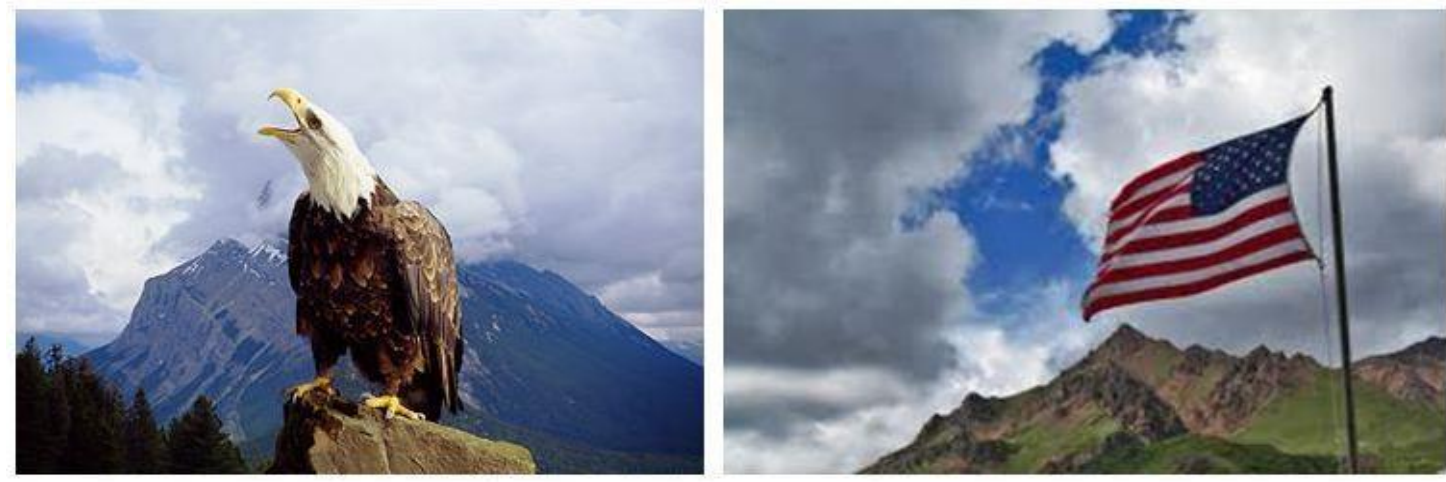

Control condition had no images. 
